\title{
Phylogenetic classification of Bartonella species by comparing groEL sequences
}

1 Unité des Rickettsies, CNRS UPRES-A 6020, Faculté de Médecine, 27 boulevard Jean Moulin, 13385

Marseille Cedex 05, France

2 Information Génétique \& Structurale, CNRS UMR 1889, 31 chemin Joseph Aiguier, 13402 Marseille cedex 20, France

\author{
Zaher Zeaiter, ${ }^{1}$ Pierre-Edouard Fournier, ${ }^{1}$ Hiroyuki Ogata ${ }^{2}$ \\ and Didier Raoult ${ }^{1}$
}

Author for correspondence: Didier Raoult. Tel: +334913243 75. Fax: +33491830390. e-mail: Didier.Raoult@medecine.univ-mrs.fr

\begin{abstract}
Bartonella is a bacterial genus classified in the $\alpha$-Proteobacteria on the basis of 16S rDNA sequence comparison. The highly conserved heat-shock chaperonin protein, GroEL, has proved to be a valuable resolving tool to classify ten Bartonella species. The groEL gene was amplified and sequenced from ten Bartonella isolates: Bartonella alsatica, Bartonella vinsonii subsp. arupensis, Bartonella taylorii, Bartonella tribocorum, Bartonella birtlesii, Bartonella henselae Marseille (URLLY8), B. henselae (90-615), B. henselae (Fizz), B. henselae (CAL-1) and $B$. henselae (SA-2). Then, phylogenetic relationships were inferred between our isolates and eight other species and subspecies from the comparison of both 165 rDNA and groEL sequences using parsimony, neighbour-joining and maximum-likelihood methods. By using groEL sequences, the first reliable classification of most known Bartonella species and subspecies was established. Four strongly supported subgroups were distinguished: firstly, the two human pathogens $B$. henselae and Bartonella quintana; secondly, a cluster including four rodent isolates, Bartonella elizabethae, B. tribocorum, Bartonella grahamii and B. taylorii; thirdly, a cluster including the $B$. vinsonii subspecies (B. vinsonii subsp. vinsonii, arupensis and berkhoffii); and lastly, B. birtlesii and 'Bartonella weissi'. ' Bartonella washoensis', B. alsatica, Bartonella doshiae, Bartonella bacilliformis and Bartonella clarridgeiae did not reliably cluster with any other Bartonella species. In addition, the groEL gene was shown to be useful in subtyping six $B$. henselae isolates into three variants: Houston, Marseille and Fizz.
\end{abstract}

Keywords: Bartonella, 16S rDNA, groEL, phylogeny, subtyping

\section{INTRODUCTION}

Bacteria within the genus Bartonella are aerobic, Gram-negative, fastidious, oxidase-negative, slowgrowing, pleiomorphic organisms, which belong to the $\alpha$-Proteobacteria on the basis of their 16S rDNA sequences (Brenner et al., 1993; Birtles et al., 1995). These bacteria are considered to be emerging pathogens (Anderson \& Neuman, 1997). Currently, 18 Bartonella species are recognized. All of them are associated with mammalian hosts. Bartonella taylorii, Bartonella elizabethae, Bartonella tribocorum and Bartonella birtlesii were isolated from rats (Birtles et al., 1995; Brenner et al., 1993; Heller et al., 1998; Bermond

Abbreviation: ITS, intergenic spacer. et al., 2000); Bartonella grahamii, Bartonella vinsonii subsp. vinsonii and Bartonella doshiae were recovered from voles (Birtles et al., 1995; Brenner et al., 1993); B. vinsonii subsp. arupensis was isolated from mice (Welch et al., 1999); Bartonella alsatica was isolated from rabbits (Heller et al., 1999); 'Bartonella weissi', Bartonella clarridgeiae, Bartonella henselae and Bartonella koehlerae were obtained from cats (Droz et al., 1999; Kelly et al., 1998; Koehler et al., 1994; Lawson \& Collins, 1996); B. vinsonii subsp. berkhoffii was cultivated from dogs (Breitschwerdt et al., 1995) and from coyotes (Chang et al., 2000); 'Bartonella washoensis' was evidenced in rodents (R. L. Regnery, personal communication); and Bartonella quintana and Bartonella bacilliformis were isolated from humans (McNee et al., 1916; Gray et al., 1990). As Bartonella species express few remarkable phenotypic characteris- 
tics, their precise identification and phylogenetic classification has mainly relied on the study of various genes. The $16 \mathrm{~S}$ rDNA sequence, which was considered to be one of the most useful and informative tools for the identification and phylogenetic studies of bacteria (Olsen \& Woese, 1993), was the first gene to be studied but has failed to establish a reliable phylogeny of Bartonella species. The high degree of conservation of this gene led to a small number of informative sites in its sequence. Thus, it does not seem to be a good tool to reveal a precise and statistically supported phylogeny at the species level (Fox et al., 1992; Hasegawa \& Hashimoto, 1993; Teichmann \& Mitchison, 1999). Other genes have been investigated to classify Bartonella species. The $16 \mathrm{~S}-23 \mathrm{~S}$ rDNA intergenic spacer (ITS) region (Roux \& Raoult, 1995) and the citrate synthase-encoding gene $(\mathrm{glt} A)$ (Birtles \& Raoult, 1996) provided better bootstrap values for the nodes than those obtained with the 16S rDNA sequence. Currently, the most recent and reliable classification of Bartonella species was established by Marston et al. (1999) who, using the $60 \mathrm{kDa}$ heat-shock proteinencoding gene ( $g r o E L)$, which is one of the two highly conserved components of the heat-shock chaperonin response system groES (Hsp10)/groEL (Hsp60) (Mayhew \& Hartl, 1996), established the relationships between nine Bartonella strains.

In the present study, sequences of the major portion of the groEL gene from ten additional Bartonella isolates were determined. From the alignment of these sequences and those available for another eight species and subspecies, the phylogenetic relationships within the Bartonella genus were inferred. The utility of this gene as a tool in subtyping $B$. henselae and $B$. quintana isolates was also tested.

\section{METHODS}

Bartonella strains and DNA extraction. The strains used in this study are summarized in Table 1. Bartonella isolates were grown on $5 \%$ sheep blood agar (bioMérieux) at $37^{\circ} \mathrm{C}$ in a $5 \% \mathrm{CO}_{2}$-enriched atmosphere. Bacteria were harvested after $7 \mathrm{~d}$ cultivation and DNA was extracted using the Chelex method (de Lamballerie et al., 1992). Supernatants containing the genomic DNAs were stored at $4{ }^{\circ} \mathrm{C}$ until their use as templates in PCR.

PCR amplification and DNA sequencing. Primers used for amplification and sequencing are presented in Table 2. Primer positions are numbered relative to the groEL gene of B. bacilliformis (Table 1). Primers were selected using the Primer3 software (Rozen \& Skaletsky, 2000; code available at http://www-genome.wi.mit.edu/genome_software/ other/primer3.html) and were purchased from Eurobio. PCRs were carried out in PTC-200 automated thermocyclers (MJ Research) using a Taq DNA polymerase kit (GibcoBRL) and primers BbHS1630.n and HSPF1D (Table 2). The $25 \mu \mathrm{l}$ reaction mixture consisted of (final concentration):

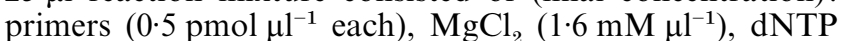
(dATP, dCTP, dGTP and dTTP) $\left(0 \cdot 2 \mathrm{mM} \mu \mathrm{l}^{-1}\right.$ each), $2 \cdot 5 \mu \mathrm{l}$ buffer $10 \times$ and Taq DNA Polymerase enzyme $\left(0.03 \mathrm{U}_{\mu} \mathrm{l}^{-1}\right)$, $5 \mu \mathrm{l}$ DNA preparation and sterile water. PCR amplification was performed under the following conditions: a 3 min denaturation at $94{ }^{\circ} \mathrm{C}$ was followed by 40 cycles of denaturation for $30 \mathrm{~s}$ at $94{ }^{\circ} \mathrm{C}$, annealing for $30 \mathrm{~s}$ at $54^{\circ} \mathrm{C}$ and extension for $90 \mathrm{~s}$ at $72^{\circ} \mathrm{C}$. The amplification was completed by holding for $7 \mathrm{~min}$ at $72{ }^{\circ} \mathrm{C}$ to allow complete extension of the PCR products. PCR products were separated by electrophoresis on $1 \%$ agarose gels, visualized by staining with ethidium bromide and then purified using the QIAquick PCR purification kit (QIAGEN) as described by the manufacturer. PCR products were sequenced in both directions using the d-Rhodamine Terminator Cycle Sequencing Ready Reaction kit (Perkin Elmer) as described by the manufacturer. Each reaction was carried out using $5 \mu \mathrm{l}$ purified DNA ( $200 \mathrm{ng}), \mathrm{d}$-Rhodamine mix $(4 \mu \mathrm{l})$ and $1 \mu \mathrm{l}$ primer $(10 \mathrm{pmol})$; sequencing primers are reported in Table 2. Conditions used for sequencing were 30 cycles of denaturation for $20 \mathrm{~s}$ at $95^{\circ} \mathrm{C}$, annealing for $10 \mathrm{~s}$ at $50^{\circ} \mathrm{C}$ and extension for $2 \mathrm{~min}$ at $60{ }^{\circ} \mathrm{C}$. Reaction products were mixed with $80 \mu 170 \%$ ethanol and $0.5 \mathrm{mM} \mathrm{MgCl}_{2}$ and, after being held for $20 \mathrm{~min}$ at room temperature in the dark, precipitated DNA was collected by centrifugation for $25 \mathrm{~min}$ at 3000 r.p.m. at room temperature. The DNA pellet was dried and resuspended in either $3 \mu 11 / 4(\mathrm{v} / \mathrm{v})$ formamide/ $1 \%$ bromophenol blue solution and then denatured by heating for $2 \mathrm{~min}$ at $95^{\circ} \mathrm{C}$ or $12 \mu \mathrm{l}$ Template Suppression reagent (Perkin Elmer). Sequencing products were resolved using an ABI 377 or an ABI 310 automated sequencer (Perkin Elmer).

Analysis of sequences and construction of phylogenetic trees. Sequence analysis was performed with the software packages ABI Prism DNA Sequencing Analysis Software version 3.0 (Perkin Elmer) and multisequence alignment was made with CLUSTAL W software, version 1.81 (Thompson et al., 1994). Phylogenetic trees were obtained from DNA sequences by using the maximum-parsimony method (DNAPARS software in PHYLIP; Felsenstein, 1989), distance methods (DNADIST, distance matrix with Kimura twoparameter or Jukes-Cantor parameters; and NEIGHBOR, neighbour-joining) and the maximum-likelihood method (DNAMLK software in PHYLIP). Phylogenetic trees were inferred from amino acid sequences using the maximumparsimony method (PROTPARS software in PHYLIP) and distance methods (PROTDIST, dayhoff PAM matrix or Kimura formula; and NEIGHBOR, neighbour-joining) Bootstrap replicates were performed to estimate the node reliability of the phylogenetic trees obtained by the three methods (Brown, 1994). Bootstrap values were obtained from 100 trees (Efron et al., 1996) generated randomly with SEQBOOT and CONSENSE in the PHYLIP software package. Only values above 90 were considered significant. Trees were drawn using the TREEVIEW version 1.5 (Page, 1996) software. Agrobacteriun tumefaciens and Brucella abortus, two other $\alpha$-Proteobacteria, were used as the outgroup in all our phylogenetic trees (Table 1). Only the neighbour-joining tree is presented in this article.

By comparing groEL sequences of $B$. henselae isolates (Marseille, SA-2, Fizz, CAL-1, 90-615 and Houston- ${ }^{\mathrm{T}}$ ) and $B$. quintana isolates (Fuller and Oklahoma), the utility of this gene in subtyping these two Bartonella species was investigated. Sequences were aligned using the CLUSTAL W software. A phylogenetic tree was constructed from the distance matrix generated by the neighbour-joining method. $B$. bacilliformis was used as outgroup. 
Table 1. Bacterial strains and sequences used in this study

\begin{tabular}{|c|c|c|c|}
\hline \multirow[t]{2}{*}{ Species/strain } & \multirow[t]{2}{*}{ Collection no./source* } & \multicolumn{2}{|c|}{ Sequence accession no.: } \\
\hline & & 16S rRNA & groEL \\
\hline Agrobacterium tumefaciens (type strain) & & D14500 & X68263 \\
\hline Bartonella alsatica IBS $382^{\mathrm{T}}$ & CIP $105477^{\mathrm{T}}$ & AJ002139 & AF299357 \\
\hline Bartonella bacilliformis (type strain) & & Z11683 & Z15160 \\
\hline Bartonella birtlesii IBS $325^{\mathrm{T}}$ & CIP $106294^{\mathrm{T}}$ & AF204274 & AF355773 \\
\hline Bartonella clarridgeiae $94-\mathrm{F} 40^{\mathrm{T}}$ & & U64691 & AF014831 \\
\hline Bartonella doshiae (type strain) & & Z31351 & AF014832 \\
\hline Bartonella elizabethae (type strain) & & L01260 & AF014834 \\
\hline Bartonella grahamii (type strain) & & Z31349 & AF014833 \\
\hline Bartonella henselae CAL-1 & $\mathrm{CDC}$ & & AF304020 \\
\hline Bartonella henselae Fizz & & & AF304022 \\
\hline Bartonella henselae Houston- $1^{\mathrm{T}}$ & & M73229 & AF014829 \\
\hline Bartonella henselae Marseille ${ }^{\mathrm{T}}$ & CIP $104756^{\mathrm{T}}$ & AF214556 & AF304019 \\
\hline Bartonella henselae SA-2 & $\mathrm{CDC}$ & & AF304021 \\
\hline Bartonella henselae 90-615 & $\mathrm{CDC}$ & & AF304023 \\
\hline Bartonella koehlerae C-29 ${ }^{\mathrm{T}}$ & ATCC $700693^{\mathrm{T}}$ & AF076237 & ND \\
\hline Bartonella quintana Fuller $^{T}$ & ATCC VR $358^{\mathrm{T}}$ & M11927 & \\
\hline Bartonella quintana Oklahoma $^{\mathrm{T}}$ & $\mathrm{CDC}$ & & AF014830 \\
\hline Bartonella taylorii $\mathrm{M}^{\mathrm{T}}$ & NCTC $12861^{\mathrm{T}}$ & Z31350 & AF304017 \\
\hline Bartonella tribocorum IBS $506^{\mathrm{T}}$ & CIP $104576^{\mathrm{T}}$ & AJ003070 & AF304018 \\
\hline Bartonella vinsonii subsp. arupensis $\mathrm{OK} 94-513^{\mathrm{T}}$ & ATCC $700727^{\mathrm{T}}$ & AF214558 & AF304016 \\
\hline Bartonella vinsonii subsp. berkhoffii (type strain) & & U26258 & AF014836 \\
\hline Bartonella vinsonii subsp. vinsonii $\mathrm{G} 7464^{\mathrm{T}}$ & & M73230 & AF014835 \\
\hline 'Bartonella washoensis' nvh1 & & AF070463 & AF071193 \\
\hline 'Bartonella weissi' FC7049UT & & AF199502 & AF071194 \\
\hline Brucella abortus (type strain) & & X13695 & M82975 \\
\hline
\end{tabular}

ND, Not determined.

* Abbreviations: CIP, Collection de l'Institut Pasteur; Paris, France; CDC, Centers for Disease Control, Atlanta, GA, USA; ATCC, American Type Culture Collection, Manassas, VA, USA; NCTC, National Collection of Type Cultures, Central Public Health Laboratory, London, UK.

Table 2. Primers used for PCR and/or sequencing

The target gene in all cases was groEL.

\begin{tabular}{|lll|}
\hline Primer* & \multicolumn{1}{c|}{ Primer sequence } & \multicolumn{1}{c|}{$\begin{array}{c}\text { Position } \\
\text { (direction) } \dagger\end{array}$} \\
\hline HSPF1d (ap, s) & 5'-GAACTNGAAGATAAGTTNGAA-3' & $180(\rightarrow)$ \\
BbHS1630.n (ap, s) $\ddagger$ & 5'-AATCCATTCCGCCCATTC-3' & $1668(\leftarrow)$ \\
HSP1 (s) & 5'-GGAAAAAGTNGGCAATGAAG-3' & $501(\rightarrow)$ \\
HSP2 (s) & 5'-GCNGCTTCTTCACCNGCATT-3' & $1412(\leftarrow)$ \\
HSPS1 (s) & 5'-AAGCNCCNGGNTTTGGTGA-3' & $865(\leftarrow)$ \\
HSPS2 (s) & 5'-TCACCAAANCCNGGNGCTT-3' & $846(\rightarrow)$ \\
HSPF2d (s) & 5'-GAAAGANCGNGTNGATGAT-3' & $1203(\rightarrow)$ \\
HSPR2d (s) & 5'-GTNATNAGAAGNCTNGCAAT-3' & $1575(\leftarrow)$ \\
\hline
\end{tabular}

* Abbreviations: ap, amplification primer; s, sequencing primer.

$\dagger$ Positions are numbered relative to the groEL gene of Bartonella bacilliformis (accession no. Z15160). Arrows indicate direction of primers $(\rightarrow$, forward; $\leftarrow$, reverse).

† Marston et al. (1999). 


\section{RESULTS}

\section{Phylogeny of Bartonella species based on comparison of $16 \mathrm{~S}$ rDNA sequences}

To obtain a contiguous alignment, 12 bases (positions 154-165) of the 16S rDNA sequence of $B$. vinsonii subsp. berkhoffii were removed. Trees inferred using the maximum-parsimony, the neighbour-joining and maximum-likelihood methods showed similar organization. Only one cluster, formed by B. elizabethae and $B$. tribocorum, was supported by elevated bootstrap values $(95,93$ and $90 \%$ using the methods cited above, respectively). $B$. henselae Marseille and $B$. henselae Houston- $1^{\mathrm{T}}$ formed one reliable cluster only when using the neighbour-joining method (98\%). In general, most of the Bartonella clusters obtained lacked statistical support, whereas branching of the two outgroup bacteria, Brucella abortus and A. tumefaciens, was statistically supported (100\%; data not shown).

\section{Phylogeny of Bartonella species based on the comparison of groEL DNA sequences}

Contiguous multiple alignment of $1188 \mathrm{bp}(72 \%$ of the entire gene sequence) of the groEL gene was carried out. Phylogenetic analysis using the maximum-parsimony, neighbour-joining (Fig. 1) and maximumlikelihood methods provided similar and reliable org- anizations. The neighbour-joining-derived trees using Jukes-Cantor or Kimura two-parameter showed similar organization, but when using the second correction method, higher bootstrap values were obtained, which were used below. Four reliable clusters were characterized. A cluster including the three $B$. vinsonii subspecies ( $B$. vinsonii subsp. vinsonii, arupensis and berkhoffii) was obtained using all three methods with significant bootstrap values $(95,93$ and $90 \%$, respectively). However, within this cluster, the organization of the three subspecies varied. Using neighbourjoining and maximum-likelihood, B. vinsonii subsp. vinsonii clustered with $B$. vinsonii subsp. arupensis, whereas using maximum-parsimony, it clustered with $B$. vinsonii subsp. berkhoffii. This variation was reflected by bootstrap values of 47,50 and $71 \%$, respectively. In a second cluster, the two $B$. henselae subspecies (Houston- $1^{\mathrm{T}}$ and Marseille) and B. quintana grouped together in all trees. This cluster was supported by higher bootstrap values using the neighbourjoining method $(90 \%)$ than both parsimony and maximum-likelihood (83 and $63 \%$, respectively). $B$. elizabethae and B. tribocorum grouped together using all three methods with significant bootstrap values $(94$, 100 and $100 \%$, respectively), which was also the case for B. grahamii and B. taylorii (bootstrap values of 100,100 and $99 \%$, respectively). Using all three methods, these two groups formed a third statistically

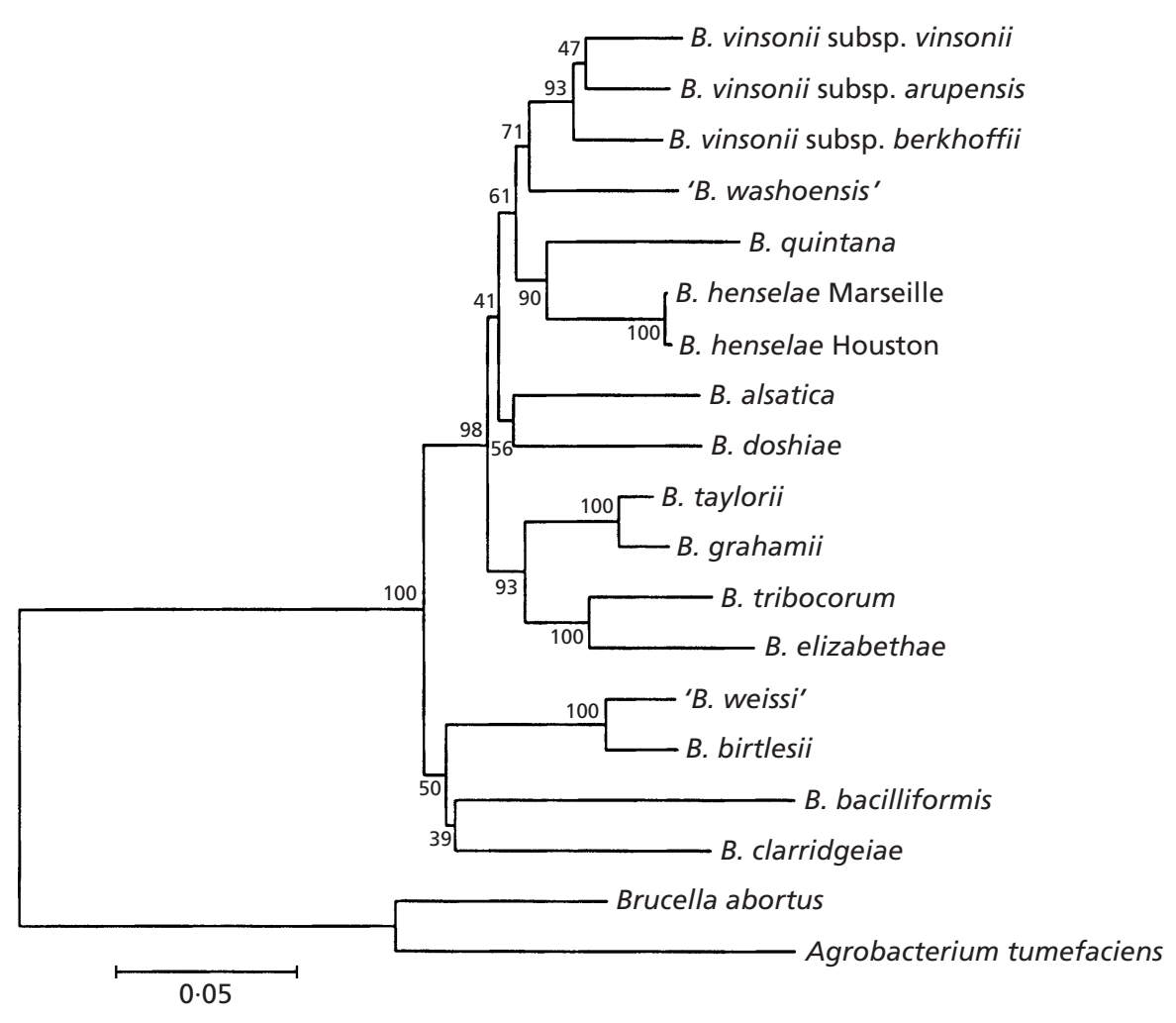

Fig. 1. Neighbour-joining tree (based on the Kimura two-parameter model of nucleotide substitution) based on the groEL nucleotide sequences. Bootstrap values at the tree nodes are based on 100 replicates. The tree was rooted with Agrobacterium tumefaciens. Bar, $5 \%$ divergence. 
supported cluster $(89,93$ and $94 \%$, respectively). $B$. birtlesii and ' $B$. weissi' formed the fourth cluster, which was statistically supported when using all three methods (100\% each). However, these bacterium clustered with $B$. clarridgeiae with low bootstrap values (53, 50 and $37 \%$, respectively). The grouping of $B$. bacilliformis, B. alsatica, 'B. washoensis' and B. doshiae observed in all three methods was not reliable. As mentioned above, classification of the two species outside the genus Bartonella, Brucella abortus and $A$. tumefaciens, was reliable and consistent in all three trees $(100 \%$ each). The phylogenetic organization obtained using the various analysis methods was supported by nucleotide substitutions at informative sites observed in the sequence alignment (data not shown). When masking the third nucleotide position, the branching order was not modified (data not shown). The groEL gene of B. koehlerae could not be amplified, but additional attempts are currently being made to resolve this problem.

\section{Phylogeny of Bartonella species based on comparison of the GroEL amino acid sequences}

The level of amino acid sequence similarity among the studied strains varied from $90.9 \%$ between $B$. bacilliformis and B. taylorii to $99 \cdot 1 \%$ between $B$. vinsonii subsp. vinsonii and berkhoffii. In the neighbour-joining-calculated trees, three clusters, $B$. henselae subsp. Marseille and Houston- $1^{\mathrm{T}}, B$. birtlesii and ' $B$. weissi', and $B$. vinsonii subsp. vinsonii and berkhoffii, were supported by sufficient bootstrap values [90, 100 and $89 \%$, respectively, when using dayhoff PAM matrix and 94,100 and $91 \%$, respectively, when using the Kimura formula (data not shown)]. When using the PROTPARS method, these three clusters where established with significant bootstrap values: 72, 100 and $93 \%$, respectively (data not shown).

\section{Subtyping of $B$. henselae and $B$. quintana species using groEL gene sequences}

The groEL gene sequences of $B$. quintana strain Oklahoma (Marston et al., 1999) and strain Fuller were $100 \%$ identical, whereas groEL gene sequences from five $B$. henselae strains (Marseille, SA-2, Fizz, CAL-1 and 90-615) were determined and compared to that of $B$. henselae strain Houston- $1^{\mathrm{T}}$. Three groEL variants were identified and were arranged in two clusters (data not shown). The first one was statistically supported and included $B$. henselae strains Houston$1^{\mathrm{T}}, 90-615$ and SA-2, whereas the second cluster did not have statistical support and it included $B$. henselae strains Marseille, CAL-1 and Fizz. Within the Marseille cluster, the sequence from strain Fizz could be differentiated from those of the two other strains.

\section{DISCUSSION}

Comparison of 16S rDNA sequences has led to many taxonomic reassessments within the genus Bartonella (Brenner et al., 1993; Birtles et al., 1995). In particular, the genera Bartonella, Rochalimaea (Brenner et al., 1993) and Grahamella (Birtles et al., 1995) were unified. However, although shown to be useful at the genus level (Olsen \& Woese, 1993), the reliability of the 16S rDNA sequence as a tool for phylogenetic studies at the species level has been questioned (Fox et al., 1992; Hasegawa \& Hashimoto, 1993). Alternative genes that may be used for phylogenetic purposes should be both highly conserved (i.e. housekeeping genes) and sufficiently variable to allow species identification (Olsen \& Woese, 1993). Several empirically chosen genes have been used in an attempt to classify the Bartonella species. The gltA (Birtles \& Raoult, 1996) and the 16S-23S ITS (Roux \& Raoult, 1995; Jensen et al., 2000) genes have been used. Resulting trees had a better resolution than those inferred from $16 \mathrm{~S}$ rDNA sequences, but many branches lacked a statistical support. A recent ITS-derived classification of Bartonella species performed in our laboratory showed reliable tree organizations, similar to groEL-derived trees (Houpikian \& Raoult, 2001). The importance of the groEL gene as a sensitive and valuable tool for bacterial species phylogeny (Viale et al., 1994) was recently highlighted. GroEL (Hsp60) is essential for protein folding, assembly and secretion (Mayhew \& Hartl, 1996). As such, this gene is present in both prokaryotes and eukaryotes. It was used in phylogenetic analysis of Borrelia species (Wallich et al., 1992), mitochondria of Euglena gracilis (Yasuhira \& Simpson, 1997), Staphylococcus species (Kwok et al., 1999), photosynthetic prokaryotes (Gupta et al., 1999), Ehrlichia species (Sumner et al., 1997; Shibata et al., 2000) and Bartonella species (Marston et al., 1999). In the latter study, the usefulness of this gene has been highlighted for the phylogenetic classification of Bartonella species, but many species were not used in this study. In the present study, groEL sequences were used to assess the classification of most of the currently known species of the genus Bartonella and their utility in the subtyping of $B$. henselae and B. quintana isolates was investigated. By comparing phylogenetic trees derived from $16 \mathrm{~S}$ rDNA sequences, it was confirmed that this gene was unable to resolve the relationships within the genus Bartonella as most branches lacked statistical support and only one reliable cluster, formed by $B$. elizabethae and B. tribocorum, was established. In contrast, trees generated using groEL sequences were much more informative. All three phylogenetic analysis methods provided similar and reliable topologies. Bartonella species were distributed in four clusters supported by significant bootstrap values. The first cluster included the worldwide distributed human pathogens $B$. henselae Houston- $1^{\mathrm{T}}$ and Marseille and $B$. quintana. The second cluster included B. elizabethae, B. tribocorum, B. grahamii and B. taylorii. Although all are associated with rodents, these species were not geographically homogeneous, as three have been isolated in Europe and one in the USA (B. elizabethae). The third cluster contained the three $B$. vinsonii subspecies: $B$. vinsonii subsp. vinsonii, arupensis and berkhoffii, all isolated in North America. In the fourth 
cluster, B. birtlesii and ' $B$. weissi' were grouped with reliable bootstrap values when using all methods for nucleotide and amino acid sequences analysis. However, phylogenetic association of these two species did not correlate with their host or geographical origin. $B$. bacilliformis, which has a limited geographical distribution, did not reliably cluster with any other Bartonella species. B. alsatica and B. doshiae, which have both been isolated from rodents in Europe, clustered together using neighbour-joining methods, but their group was not statistically supported. The classification of all other Bartonella species studied was uncertain. In the future, the study of novel isolates may strengthen the classification of these Bartonella. Some of the clusters inferred from comparison of groEL sequences were consistent with previous studies. $B$. grahamii and B. elizabethae, and B. quintana and $B$. henselae clusters had previously been established using glt $A$ sequences (Birtles \& Raoult, 1996). These two clusters, as well as that formed by $B$. vinsonii subsp. berkhoffii and $B$. vinsonii subsp. vinsonii, were also described by Marston et al. (1999) based on groEL sequence analysis. When examining amino acid sequences deduced from groEL nucleotide sequences, a reliable phylogenetic organization for bartonellae was not obtained, although three reliable branches were established, which may be explained by the high degree of amino acid sequence conservation among Bartonella species. Additionally, this gene was useful in the subtyping of $B$. henselae isolates, but failed with those of $B$. quintana, confirming that this species is more homogeneous than $B$. vinsonii or $B$. henselae. In conclusion, the groEL gene was shown to be more reliable than any of the previously studied tools to infer precise phylogenetic relationships among Bartonella spp.

\section{ACKNOWLEDGEMENTS}

The authors thank Michael F. Minnick for reviewing the manuscript and Alia Ben Kahla for helping in tree construction.

\section{REFERENCES}

Anderson, B. E. \& Neuman, M. A. (1997). Bartonella spp. as emerging human pathogens. Clin Microbiol Rev 10, 203-219.

Bermond, D., Heller, R., Barrat, F. \& \& 7 other authors (2000). Bartonella birtlesii sp. nov., isolated from small mammals (Apodemus spp.). Int J Syst Evol Microbiol 50, 1973-1979.

Birtles, R. J. \& Raoult, D. (1996). Comparison of partial citrate synthase gene $(\mathrm{glt} A)$ sequences for phylogenetic analysis of Bartonella species. Int J Syst Bacteriol 46, 891-897.

Birtles, R. J., Harrison, T. G., Saunders, N. A. \& Molyneux, D. H. (1995). Proposals to unify the genera Grahamella and Bartonella, with descriptions of Bartonella talpae comb. nov., Bartonella peromysci comb. nov., and three new species, Bartonella grahamii sp. nov., Bartonella taylorii sp. nov., and Bartonella doshiae sp. nov. Int J Syst Bacteriol 45, 1-8.

Breitschwerdt, E. B., Kordick, D. L., Malarkey, D. E., Keene, B., Hadfield, T. L. \& Wilson, K. (1995). Endocarditis in a dog due to infection with a novel Bartonella subspecies. J Clin Microbiol 33, 154-160.

Brenner, D. J., O'Connor, S., Winkler, H. H. \& Steigerwalt, A. G. (1993). Proposals to unify the genera Bartonella and Rochalimaea, with descriptions of Bartonella quintana comb. nov., Bartonella vinsonii comb. nov., Bartonella henselae comb. nov., and Bartonella elizabethae comb. nov., and to remove the family Bartonellaceae from the order Rickettsiales. Int $J$ Syst Bacteriol 43, 777-786.

Brown, J. K. (1994). Bootstrap hypothesis tests for evolutionary trees and other dendrograms. Proc Natl Acad Sci USA 91, 12293-12297.

Chang, C. C., Kasten, R. W., Chomel, B. B., Simpson, D. C., Hew, C. M., Kordick, D. L., Heller, R., Piemont, Y. \& Breitschwerdt, E. B. (2000). Coyotes (Canis latrans) as the reservoir for a human pathogenic Bartonella sp.: molecular epidemiology of Bartonella vinsonii subsp. berkhoffii infection in coyotes from central coastal California. J Clin Microbiol 38, 4193-4200.

Droz, S., Chi, B., Horn, E., Steigerwalt, A. G., Whitney, A. M. \& Brenner, D. J. (1999). Bartonella koehlerae sp. nov., isolated from cats. J Clin Microbiol 37, 1117-1122.

Efron, B., Halloran, E. \& Holmes, S. (1996). Bootstrap confidence levels for phylogenetic trees [corrected and republished article originally printed in Proc Natl Acad Sci USA 1996, 93 7085-7090]. Proc Natl Acad Sci US A 93, 13429-13434.

Felsenstein, J. (1989). PHYLIP - Phylogeny inference package (version 3.2). Cladistics 5, 164-166.

Fox, G. E., Wisotzkey, J. D. \& Jurtshuk, P., Jr (1992). How close is close: 16S rRNA sequence identity may not be sufficient to guarantee species identity. Int J Syst Bacteriol 42, 166-170.

Gray, G. C., Johnson, A. A., Thornton, S. A., Smith, W. A., Knobloch, J., Kelley, P. W., Obregon Escudero, L., Arones Huayda, M. \& Wignall, F. S. (1990). An epidemic of Oroya fever in the Peruvian Andes. Am J Trop Med Hyg 42, 215-221.

Gupta, R. S., Mukhtar, T. \& Singh, B. (1999). Evolutionary relationships among photosynthetic prokaryotes (Heliobacterium chlorum, Chloroflexus aurantiacus, cyanobacteria, Chlorobium tepidum and proteobacteria): implications regarding the origin of photosynthesis. Mol Microbiol 32, 893-906.

Hasegawa, M. \& Hashimoto, T. (1993). Ribosomal RNA trees misleading?, Nature 361, 23.

Heller, R., Riegel, P., Hansmann, Y. \& 7 other authors (1998). Bartonella tribocorum sp. nov., a new Bartonella species isolated from the blood of wild rats. Int J Syst Bacteriol 48, 1333-1339.

Heller, R., Kubina, M., Mariet, P. \& 9 other authors (1999). Bartonella alsatica sp. nov., a new Bartonella species isolated from the blood of wild rabbits. Int J Syst Bacteriol 49, 283-288.

Houpikian, P. \& Raoult, D. (2001). 16S/23S rRNA intergenic spacer regions for phylogenetic analysis, identification, and subtyping of Bartonella species. J Clin Microbiol 39, 2768-2778. Jensen, W. A., Fall, M. Z., Rooney, J., Kordick, D. L. \& Breitschwerdt, E. B. (2000). Rapid identification and differentiation of Bartonella species using a single-step PCR assay. J Clin Microbiol 38, 1717-1722.

Kelly, P. J., Rooney, J. J., Marston, E. L., Jones, D. C. \& Regnery, R. L. (1998). Bartonella henselae isolated from cats in Zimbabwe. Lancet 351, 1706.

Koehler, J. E., Glaser, C. A. \& Tappero, J. W. (1994). Rochalimaea henselae infection. A new zoonosis with the domestic cat as reservoir. JAMA 271, 531-535.

Kwok, A. Y., Su, S. C., Reynolds, R. P., Bay, S. J., Av-Gay, Y., Dovichi, N. J. \& Chow, A. W. (1999). Species identification and 
phylogenetic relationships based on partial HSP60 gene sequences within the genus Staphylococcus. Int J Syst Bacteriol 49, 1181-1192.

de Lamballerie, X., Zandotti, C., Vignoli, C., Bollet, C. \& de Micco, P. (1992). A one-step microbial DNA extraction method using 'Chelex 100' suitable for gene amplification. Res Microbiol 143, 785-790.

Lawson, P. A. \& Collins, M. D. (1996). Description of Bartonella clarridgeiae sp. nov. isolated from the cat of a patient with Bartonella henselae septicemia. Med Microbiol Lett 5, 64-73.

McNee, J. W., Renshaw, A. \& Brunt, E. H. (1916). 'Trench fever': a relapsing fever occurring with the British Forces in France. $\mathrm{Br}$ Med J 12, 225-234.

Marston, E. L., Sumner, J. W. \& Regnery, R. L. (1999). Evaluation of intraspecies genetic variation within the $60 \mathrm{kDa}$ heat-shock protein gene (groEL) of Bartonella species. Int $J$ Syst Bacteriol 49, 1015-1023.

Mayhew, M. \& Hartl, F.-U. (1996). Molecular chaperon proteins. In Escherichia coli and Salmonella: Cellular and Molecular Biology, 2nd edn, pp. 922-937. Washington, DC: American Society for Microbiology.

Olsen, G. J. \& Woese, C. R. (1993). Ribosomal RNA: a key to phylogeny. FASEB J 7, 113-123.

Page, R. D. M. (1996). TREEVIEW: an application to display phylogenetic trees on personal computers. Comput Appl Biosci 12, 357-358.

Roux, V. \& Raoult, D. (1995). Inter- and intraspecies identification of Bartonella (Rochalimea) species. J Clin Microbiol 33, 1573-1579.

Rozen, S. \& Skaletsky, H. (2000). Primer3 on the WWW for general users and for biologist programmers. Methods Mol Biol 132, 365-386.
Shibata, S., Kawahara, M., Rikihisa, Y., Fujita, H., Watanabe, Y., Suto, C. \& Ito, T. (2000). New Ehrlichia species closely related to Ehrlichia chaffeensis isolated from Ixodes ovatus ticks in Japan. J Clin Microbiol 38, 1331-1338.

Sumner, J. W., Nicholson, W. L. \& Massung, R. F. (1997). PCR amplification and comparison of nucleotide sequences from the groESL heat shock operon of Ehrlichia species. J Clin Microbiol 35, 2087-2092.

Teichmann, S. A. \& Mitchison, G. (1999). Is there a phylogenetic signal in prokaryote proteins?, J Mol Evol 49, 98-107.

Thompson, J. D., Higgins, D. G. \& Gibson, T. J. (1994). CLUSTAL $\mathrm{W}$ : improving the sensitivity of progressive multiple sequence alignment through sequence weighting, position-specific gap penalties and weight matrix choice. Nucleic Acids Res 22, 4673-4680.

Viale, A. M., Arakaki, A. K., Soncini, F. C. \& Ferreyra, R. G. (1994). Evolutionary relationships among eubacterial groups as inferred from GroEL (chaperonin) sequence comparisons. Int $J$ Syst Bacteriol 44, 527-533.

Wallich, R., Helmes, C., Schaible, U. E., Lobet, Y., Moter, S. E., Kramer, M. D. \& Simon, M. M. (1992). Evaluation of genetic divergence among Borrelia burgdorferi isolates by use of OspA, fla, HSP60, and HSP70 gene probes. Infect Immun 60, 48564866.

Welch, D. F., Carroll, K. C., Hofmeister, E. K., Persing, D. H., Robison, D. A., Steigerwalt, A. G. \& Brenner, D. J. (1999). Isolation of a new subspecies, Bartonella vinsonii subsp. arupensis, from a cattle rancher: identity with isolates found in conjunction with Borrelia burgdorferi and Babesia microti among naturally infected mice. J Clin Microbiol 37, 2598-2601.

Yasuhira, S. \& Simpson, L. (1997). Phylogenetic affinity of mitochondria of Euglena gracilis and kinetoplastids using cytochrome oxidase I and hsp60. J Mol Evol 44, 341-347. 